\title{
Operando diagnostics of cathode materials based on novel sodium iron titanites
}

\author{
V. Shapovalov' ${ }^{1}$ A. Guda ${ }^{1}$, V. Butova ${ }^{1}$, A. Aboraia ${ }^{1}$, I. Shukaev², A. Soldatov ${ }^{1}$ \\ ${ }^{1}$ Smart Materials Research Institute, Southern Federal University, Rostov-on-Don, Russia, ${ }^{2}$ Department of Chemistry, Southern \\ Federal University, Rostov-on-Don, Russia \\ viks@sfedu.ru
}

A set of sodium iron titanite samples with general formula $\mathrm{Na}_{x} \mathrm{Fe}^{+2}{ }_{x / 2} \mathrm{Ti}_{2-x / 2} \mathrm{O}_{4}$ was prepared using solid-state synthesis in an inert atmosphere to test for application as cathode materials for Na-ion batteries. These materials have several advantages over analogues with $\mathrm{Fe}^{3+}$, demonstrating better sodium ion conductivity and higher $\mathrm{Na}+$ ions capacity without phase transition or destruction of the structure. [1] In the course of the investigation, several compositions of a new compound were obtained with NSIT-like structure type similar to $\mathrm{Na}_{0.9} \mathrm{Fe}^{3+}{ }_{0.9} \mathrm{Ti}_{1.1} \mathrm{O}_{4}$. Among them, composition with $\mathrm{x}=0.9$ was selected due to its electrochemical performance and structural peculiarity. From the crystallographic point of view, formation of phases in $\mathrm{Na}_{x} \mathrm{Fe}^{+2}{ }_{\mathrm{x} / 2} \mathrm{Ti}_{2-x / 2} \mathrm{O}_{4}$ system with $\mathrm{Na}_{0.9} \mathrm{Fe}^{3+}{ }_{0.9} \mathrm{Ti}_{1.1} \mathrm{O}_{4}$ structure (having $\mathrm{Fe}^{3+}$ ions mixed with $\mathrm{Ti}^{4+}$ ions) is rather unusual due to different radii of mixing ions $\left(\mathrm{Fe}^{2+}=0.92\right.$ $\left.\AA, \mathrm{Fe}^{3+}=0.785 \AA, \mathrm{Ti}^{+4}=0.745 \AA(\mathrm{CN}=6)[2]\right)$.

The $\mathrm{Na}_{0.9} \mathrm{Fe}^{3+}{ }_{0.9} \mathrm{Ti}_{1.1} \mathrm{O}_{4}$ was further studied by operando XANES spectroscopy. The sample was placed as a cathode inside custom electrochemical cell with glassy carbon X-Ray transparent windows. Li foil was used as anode and 1M LiPF6 in 1:1 EC:DMC commercial solution (Sigma) was used as electrolyte. The cell was cycled in 1.6 to $4.5 \mathrm{~V}$ range with current of C/20. Operando Fe Kedge XANES spectra were measured with the R-XAS Looper (Rigaku, Japan) laboratory X-Ray absorption spectrometer.

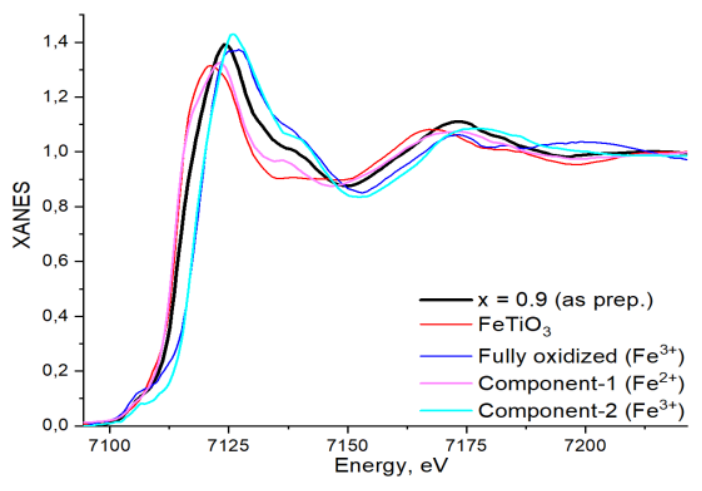

Figure 1. Principal components extracted from the series of experimental spectra using PCA, compared to experimental spectra of several reference compounds.

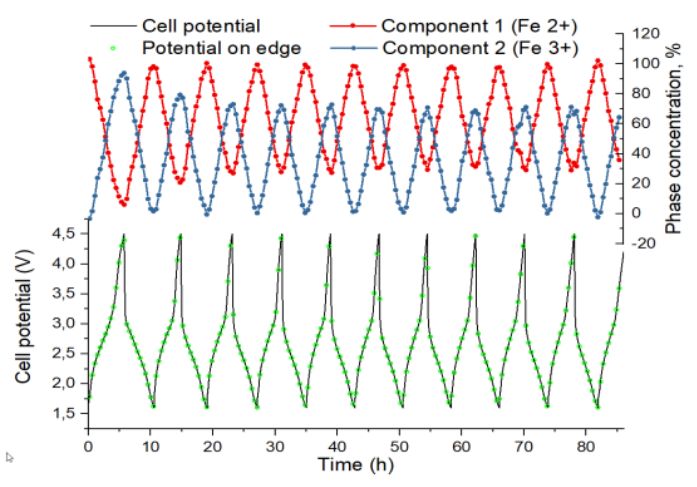

Figure 2. Cell potential and phase concentrations from PCA as a function of time (markers correspond to individual spectra).

In total 200 spectra were collected for $\mathrm{Na}_{\mathrm{x}} \mathrm{Fe}^{+2}{ }_{\mathrm{x} / 2} \mathrm{Ti}_{2-\mathrm{x} / 2} \mathrm{O}_{4}$ sample with $\mathrm{x}=0.9$ during 10 consecutive cycles, which were further analyzed by PCA to extract spectra of phases participating the electrochemical process and corresponding phase content diagrams. 2 components were successfully extracted (fig. 1). Component corresponding to a $\mathrm{Fe}^{2+}$ phase shows good agreement with $\mathrm{FeTiO}_{3}$ reference in terms of absorption edge position and overall profile of the spectrum. On the other hand, agreement with the spectrum of as-prepared sample is far from decent. Component corresponding to a $\mathrm{Fe}^{3+}$ phase shows good agreements with a reference compound (reference sample, fully oxidized in air). Comparison with theoretical spectra for various structural models have shown decent agreement of $\mathrm{Fe}^{2+}$ phase with the spectrum of freudenbergite. Fig. 2 shows the cell potential and phase concentrations from PCA as a function of time. One can clearly see the decrease in $\mathrm{Fe}^{2+} / \mathrm{Fe}^{3+}$ conversion rate during first 3 cycles, after that the rate remains stable and conversion is highly reversible. This decrease in conversion rate, as well as lack of agreement between $\mathrm{Fe}^{2+}$ phase from PCA and as prepared sample, might be accounted by electrochemical substitution of $\mathrm{Na}$ with Li that takes place during cycling in Li-based cell, which causes the change in local atomic and electronic structure of material, possibly leading to partially blocked or collapsed ion transfer channels. The degree and details of such substitution are subject for study by operando XRD and Mössbauer spectroscopy.

[1] Rajagopalan et al., (2017) Adv. Mater. 29

[2] Shannon, R.D. (1976), Acta Crystallogr. Sect. A 32, 751-767

\section{Keywords: Na-ion batteries; cathode materials; operando XAS; sodium iron titanites}

Authors would like to acknowledge the financial support of Russian Foundation for Basic Research in the framework of grant 20-3270227

Acta Cryst. (2021), A77, C684 